\title{
ESTRUCTURAS DESPLEGABLES: SISTEMAS TIPO TIJERA ${ }^{1}$
}

\author{
Natalia Torres Londoño \\ Hugo Alkmim de Matos ${ }^{3}$ \\ SMiA. Structural Morphology in Architecture ${ }^{4}$
}

DOI: $10.5752 / P .2316-1752.2017 v 24 n 35 p 16$

\section{Resumen}

Taller sobre estructuras desplegables impartido en la PUC Minas en la ciudad de Belo Horizonte. Liderado por el grupo de investigación SMiA bajo la coordinación de los miembros Hugo Alkmim de Matos y Natalia Torres y con la colaboración del LEFAD (Laboratorio de Fabricación Digital). El objetivo principal es la enseñanza de nuevas estrategias

\footnotetext{
1. Este artículo se basa en la investigación en curso de Natalia Torres, en el programa de Doctorado Tecnología de la Arquitectura, de la Edificación y el Urbanismo. UPC, bajo la dirección de Ramón Sastre y Xavier Gimferrer.

2. Arquitecta y Magister en Construcción por la Universidad Nacional de Colombia. UNAL. Candidata a doctor en el programa de Tecnología de la Arquitectura, de la Edificación y el Urbanismo. UPC. Investigadora en el Laboratorio de Innovación y Tecnología en la Arquitectura. LiTA - UPC. Cofundadora del grupo de investigación SMiA. Email: natalia.paola.torres@upc.edu.

3. Arquitecto por la Pontificia Universidad Católica de Minas Gerais (PUC Minas) y Magister en el programa de Tecnología de la Arquitectura, de la Edificación y el Urbanismo. UPC. Investigador en el grupo de investigación SMiA. Profesor invitado en el Departamento de Arquitectura y Urbanismo de la PUC Minas. Email: hugoamatos@gmail.com. 4. SMiA. Structural Morphology in Architecture. Grupo de Investigación sobre estructuras no convencionales en la arquitectura. Web: www.smia-experimental.com. Email: info@smia-experimental.com.
} 
de proyecto presentando el sistema tipo tijera como una alternativa de diseño modular, ligero y transformable. La metodología se basa en el armado de maquetas que incorporan la tecnología de la impresión $3 d$ en sistemas de conexiones, creando nuevas herramientas didácticas para entender este tipo de estructuras. El taller finaliza con la construcción de un pabellón en madera, donde el estudiante se enfrenta al cambio de escala y a los procesos reales de fabricación y montaje de una estructura desplegable.

Palabras clave: Desplegables. Sistema tipo tijera. Modular. Plegable. Construcción ligera. 


\section{DEPLOYABLE STRUCTURES: SCISSOR-TYPE SYSTEM}

\section{Abstract}

Deployable structures workshop taught at the PUC Minas in the city of Belo Horizonte. Leaded by the SMiA research group with the coordination of the members Hugo Alkmim de Matos and Natalia Torres with the collaboration of the LEFAD (Digital Fabrication Lab / PUC Minas). The main objective is the teaching of new project strategies presenting the scissor-type system as an alternative of modular, light and transformable design. The methodology is based on the assembly of models that incorporate the technology of 3D printing in connection systems, creating new didactic tools to understand these type of structures. The workshop ends with the construction of a wooden pavilion, where the student faces the change of scale and the real processes of manufacturing and assembly of a deployable structure.

Keywords: Deployable. Scissor-type system. Modular. Folding. Lightweight construction.
ESTRUTURAS RETRÁTEIS: SISTEMA DE TESOURAS

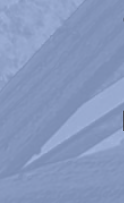

Workshop sobre estruturas retráteis realizado na PUC Minas, na cidade de Belo Horizonte. Dirigido pelo grupo de investigação SMiA sob a coordenação dos membros Hugo Alkmim de Matos e Natalia Torres e com a colaboração do LEFAD (Laboratório de Fabricação Digital / PUC Minas). O principal objetivo é o ensino de novas estratégias de projeto que apresentam o sistema tipo tesoura como alternativa de design modular, leve e transformável. A metodologia se baseia na montagem de maquetes que incorporam a tecnologia dos sistemas de impressão digital para a fabricação de conexões, criando novas ferramentas didáticas para entender esse tipo de estrutura. A oficina tem como produto a construção de um pavilhão de madeira, onde o estudante se depara com a mudança de escala e os processos reais de fabricação e montagem de uma estrutura retrátil.

Palavras-chaves: Sistema desdobrável. Tipo tesoura. Modular. Dobrável. Construção leve. 


\section{SMiA. Structural Morphology in Architecture}

Grupo de investigación perteneciente al LITA (Laboratorio de Innovación y Tecnología de la Arquitectura de la Universidad Politécnica de Cataluña). SMiA promueve la aplicación de las estructuras no convencionales, denominadas así por su poca aplicación en la arquitectura y el diseño. El campo de estudio específico refiere a la investigación y análisis de las estructuras desplegables, tensegrity, recíprocas y tenso estructuras (figura 1), las cuales se caracterizan por las siguientes ventajas:

Aprovechamiento máximo con respecto a su peso y economía de coste.

Modulación en elementos y componentes estructurales.

Rapidez de ejecución, ahorro en mano de obra y trabajo in situ.

Fácil transporte.

Aplicación en estructuras temporales y permanentes.

Montaje rápido.

Posibilidad de desmontaje y reutilización de la estructura.

Adaptabilidad a diferentes contextos 

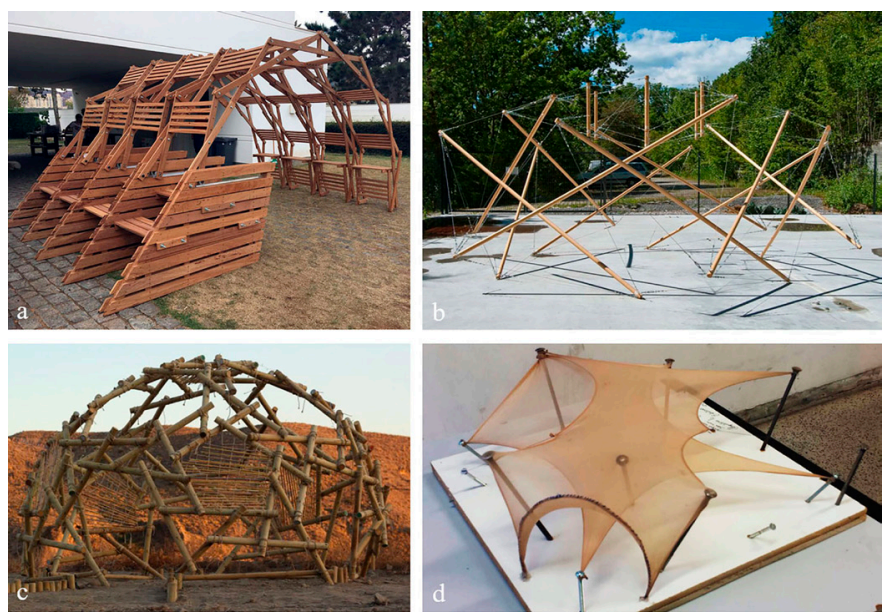

Figura 01 | Estructuras no convencionales. Proyectos desarrollados por SMiA. a) Estructura desplegable. Pabellón "Xuê". Brasil. b) Estructura tensegrity. Prototipo TG3. Alemania. c) Estructura recíproca. Pabellón Pentahex. España. d) Tenso estructura. Modelo a escala. Brasil. Fuente: www.smia-experimental.com

El objetivo principal es promover la investigación, el desarrollo y la innovación tecnológica $(\mid+D+I)$ de este tipo de estructuras, con actividades ligadas a la incorporación de nuevas herramientas tecnológicas en el cálculo, modelado y construcción. Ofrecer nuevas alternativas de diseño a través del estudio de la morfología estructural de sistemas constructivos transformables.

La difusión del conocimiento se logra gracias a la Red académica (figura 2), interdisciplinar y colaborativa entre SMiA 
y universidades, que permite el desarrollo de diferentes talleres y dan a conocer la viabilidad constructiva de este tipo de estructuras. En esta oportunidad con la colaboración y participación de la PUC Minas, en Brasil.

SMiA como grupo de investigación está dirigido a estudiantes, profesionales, investigadores, en el campo del diseño, la arquitectura, el arte, la ingeniería y demás campos afines que buscan explorar, construir, imaginar, jugar y crear nuevos conceptos arquitectónicos a partir de la geometría y la morfología estructural.

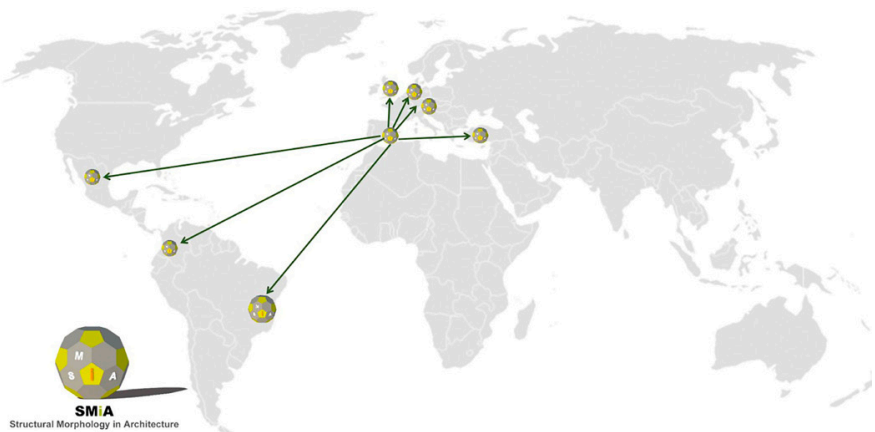

Figura 02 | Red académica, interdisciplinar y colaborativa SMiA. Universidad Politécnica de Cataluña, España. Universidad de Nottingham Trent, Inglaterra. Universidad Internacional de Cataluña, España. ILEK. Instituto de estructuras livianas y diseño conceptual, Alemania. Pontificia Universidad Javeriana, Colombia, Instituto Tecnológico de Monterrey, México. TensoRed, Red Latinoamérica de Tenso estructuras y Pontificia Universidad Católica de Minas Gerais, Brasil. Fuente: Imagen elaborada por los autores. 


\section{Introducción}

Esta publicación describe el resultado del Workshop de Estructuras Desplegables realizado por el grupo de investigación SMiA, en la ciudad de Belo Horizonte. Para un mejor entendimiento de los resultados se definen los principales conceptos sobre estructuras desplegables, el sistema tipo tijera y su respectiva clasificación.

A continuación, se detalla la metodología y las actividades realizadas con base en el armado de maquetas, herramienta fundamental en el entendimiento de las estructuras desplegables. Los resultados logrados son expuestos en una galería de imágenes que refieren a tablas descriptivas, junto con las fotografías de los modelos físicos realizados por los estudiantes.

Finalmente se propone como actividad complementaria, la construcción de un pabellón desplegable en madera, que incorpora todos los conceptos aprendidos. El pabellón Xuê tiene como principal objetivo demostrar la viabilidad constructiva de las estructuras desplegables en una aplicación arquitectónica.

La práctica constructiva permite a los estudiantes trabajar en equipo en un formato colaborativo, donde se enfrentan al reto del cambio de escala, al peso real de la estructura, al diseño de mecanismos, de detalles, al comportamiento de 
los materiales y al desarrollo de soluciones eficientes para los procesos de ensamble, montaje, pliegue y despliegue del prototipo planteado.

\section{Estructuras desplegables}

Una estructura desplegable es aquella que presenta movimiento total o de sus partes a partir de mecanismos para lograr un aumento o una nueva configuración del volumen. Estas estructuras pueden transformarse según las necesidades de cada diseño, obteniendo ventajas como la liviandad, la modulación de los elementos, facilidad en el ensamble y montaje de elementos, eficiencia estructural y plegabilidad para facilitar su almacenamiento o transporte a un nuevo emplazamiento.

La aplicación de estos sistemas en la arquitectura ha sido desarrollada desde la antigüedad por diferentes pueblos nómadas que construyeron refugios temporales basándose en conceptos de diseño inspirados en formas de la naturaleza, con el objetivo de construir viviendas con estructuras ligeras, plegables y de rápido montaje (figura 3).

La viabilidad constructiva de este tipo de estructuras ha alcanzado grandes avances gracias a los nuevos materiales y a los adelantos tecnológicos en mecanismos para la fabricación y para el diseño. El interés por las estructuras desplegables y su aplicación han generado cada vez más el 
desarollo de la movilidad estructural, permitiendo innovaciones en el campo de la arquitectura y la ingenieria.
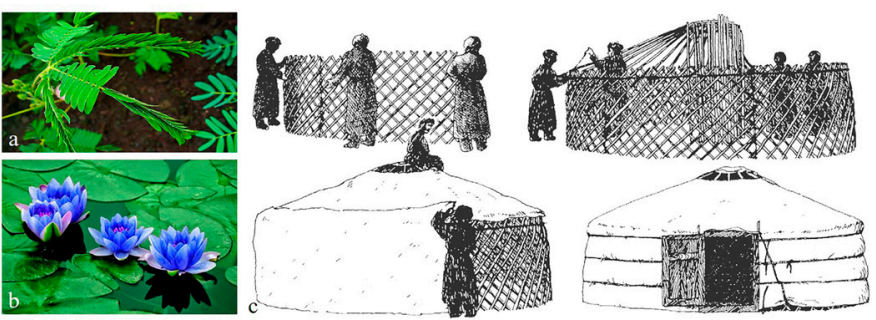

Figura 03 | La naturaleza como inspiración en el concepto de estructuras desplegables. a) Mimosa púdica. Esta planta se caracteriza por el cierre de sus hojas al tacto, principio de plegabilidad. Fuente: http://escuelangela.blogspot.com.es/ b) Proceso de apertura de una de flor de loto. Fuente: http:/floresmanizales.blogspot.com.es/ c) Proceso de montaje de una yurta. Muro plegable compuesto por un tejido de barras de sauce. Fuente: http:// www.graphics.com/

Al referirse a las estructuras desplegables existe una amplia gama de aplicaciones y su clasificación se define según el tipo de movimiento, el sistema utilizado o comportamiento de los materiales (Fenci y Currie, 2017). Para delimitar el tema tratado en esta investigación, partimos de la tabla de clasificación realizada por Stevenson (2011), que describe los tipos de transformación que puede tener una estructura: giratorio, retráctil, desplegable, plegable y deformable (figura 4). 


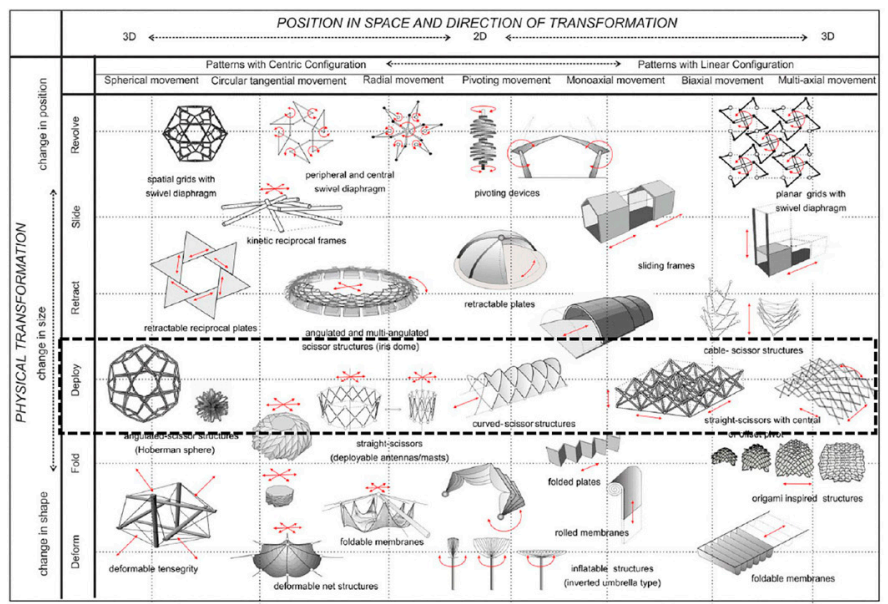

Figura 04 | Clasificación según la transformación de las estructuras (Stevenson, 2011). El recuadro punteado corresponde al campo de estudio para este artículo: Estructuras que se despliegan a partir del sistema tipo tijera.

Stevenson (2011) intitula el tema específico a tratar en esta publicación como estructuras que se despliegan. En el desarrollo de este artículo se denomina como STT (Sistema Tipo Tijera), debido a las barras articuladas que conforman este sistema.

Los principales pioneros en la aplicación de estructuras con el STT en arquitectura refieren a los arquitectos españoles Emilio Pérez Piñero y Félix Escrig, que proponen superficies desplegables a partir de barras rectas (Puertas del Río,1989) y (Escrig, 2012). Hoberman, desarrolla con un 
mayor avance tecnológico, el diseño de mecanismos para superficies curvas desplegables con barras anguladas. A nivel investigativo autores como Gantes (2004) y Temmerman (Roovers, Alegria y Temmerman, 2013) entre otros, analizan el comportamiento de este tipo de estructuras y el planteamiento de múltiples configuraciones espaciales. O casos de diseño industrial como el sistema para sillas plegables de Yuya Ushida (figura 5).

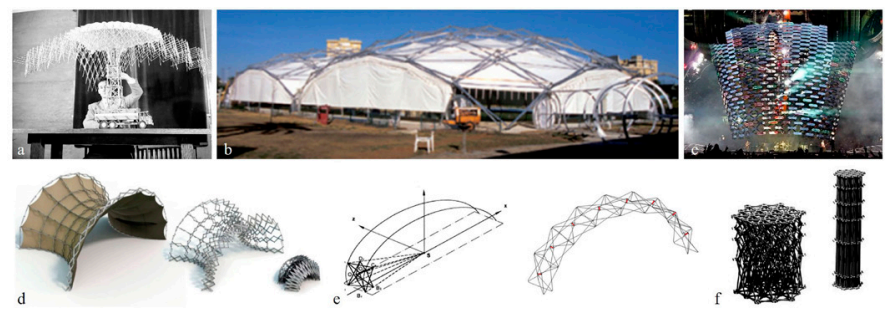

Figura 05 | a) Maqueta anteproyecto Emilio Pérez Piñero. Teatro Ambulante para 500 personas. 1961. Puertas del Río (1989). b) Cubierta para la piscina de San Pablo en Sevilla. Félix Escrig. Associació de Consultors d'Estructures (2014). c) Pantalla de video desplegable. Gira 360 U2. Fuente: http://www.hoberman.com/ d) Superficies alabeadas con el STT. Roovers, K., Alegria, L., y DeTemmerman, N (2013). e) Diseño de arcos desplegables a partir de elipses. Gantes, C. y Konitopoulou, E (2004). f) Silla desplegable. Diseño Yuya Ushida. Fuente: http://www.designrefugee.org/

\section{Sistema tipo tijera. STT}

Se define un sistema tijera como la articulación de dos barras o planos en un punto central, posicionado sobre el eje longitudinal de los elementos a articular. EI STT permite el 
giro de un elemento con respecto a otro sin que puedan separarse (Candela, Pérez E, Calatrava, Escrig y Pérez J, 1993), el encadenamiento de estos módulos forma una agrupación de tijeras que generan una variedad de configuraciones geométricas de redes desplegables planas o tridimensionales (figura 6).

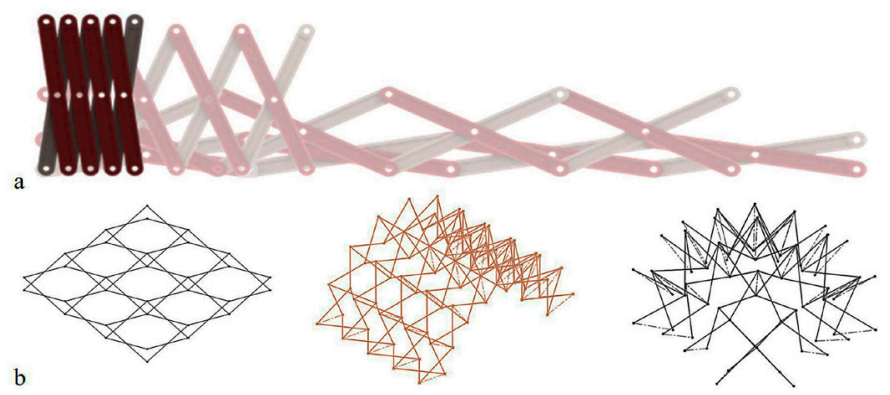

Figura 06 | a) Agrupación plana de módulos de tijeras. b) Ejemplo de algunas configuraciones espaciales a partir de STT. Fuente: Imagen elaborada por los autores.

Para configurar una agrupación de tijeras es necesario determinar la posición de los puntos de articulación que se ubican en los extremos de cada elemento, estos permiten enlazar una tijera con la siguiente y así sucesivamente. Si los puntos de articulación forman un ángulo diferente a $180^{\circ}$, se denominan tijeras anguladas y si las articulaciones forman un ángulo de $180^{\circ}$ son tijeras rectas (figura 7). 


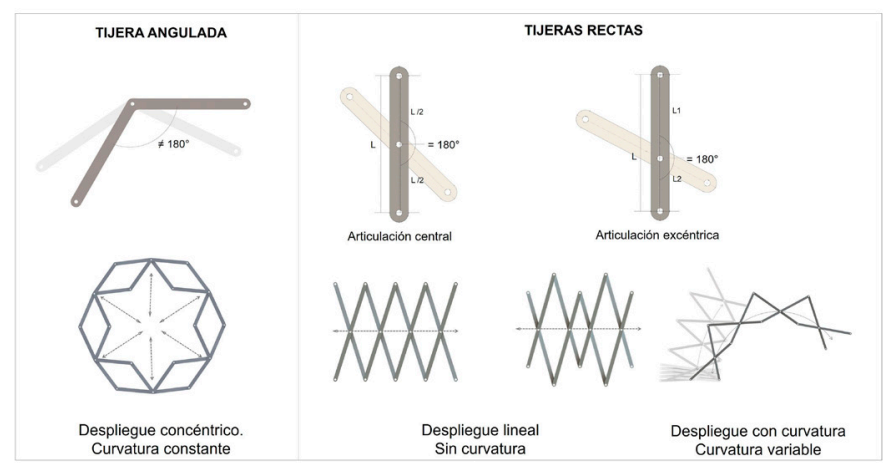

Figura 07 | Denominación de tijeras según posición de las articulaciones y su tipo de despliegue. Fuente: Imagen elaborada por los autores.

Es importante señalar que para lograr el correcto pliegue y despliegue de una agrupación de tijeras, es necesario cumplir la condición de plegado definida en la siguiente ecuación (figura 8):

$$
a+b=c+d
$$

Definidas las tipologías de tijeras y cumpliendo la condición de plegado, se propone una clasificación ${ }^{5}$ de las posibles configuraciones que se pueden lograr, señalando las características de despliegue y la posición de la articulación central (figura 9).

5. Esta clasificación pretende ser una guía para explorar, reinterpretar, combinar sistemas o proponer nuevas alternativas de configuraciones espaciales basadas en la plegabilidad y movilidad estructural. 

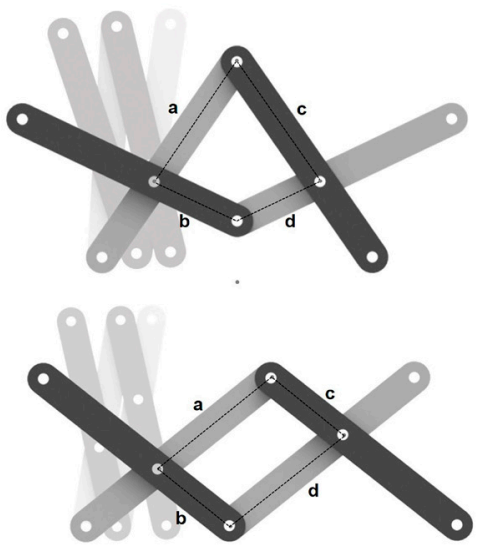


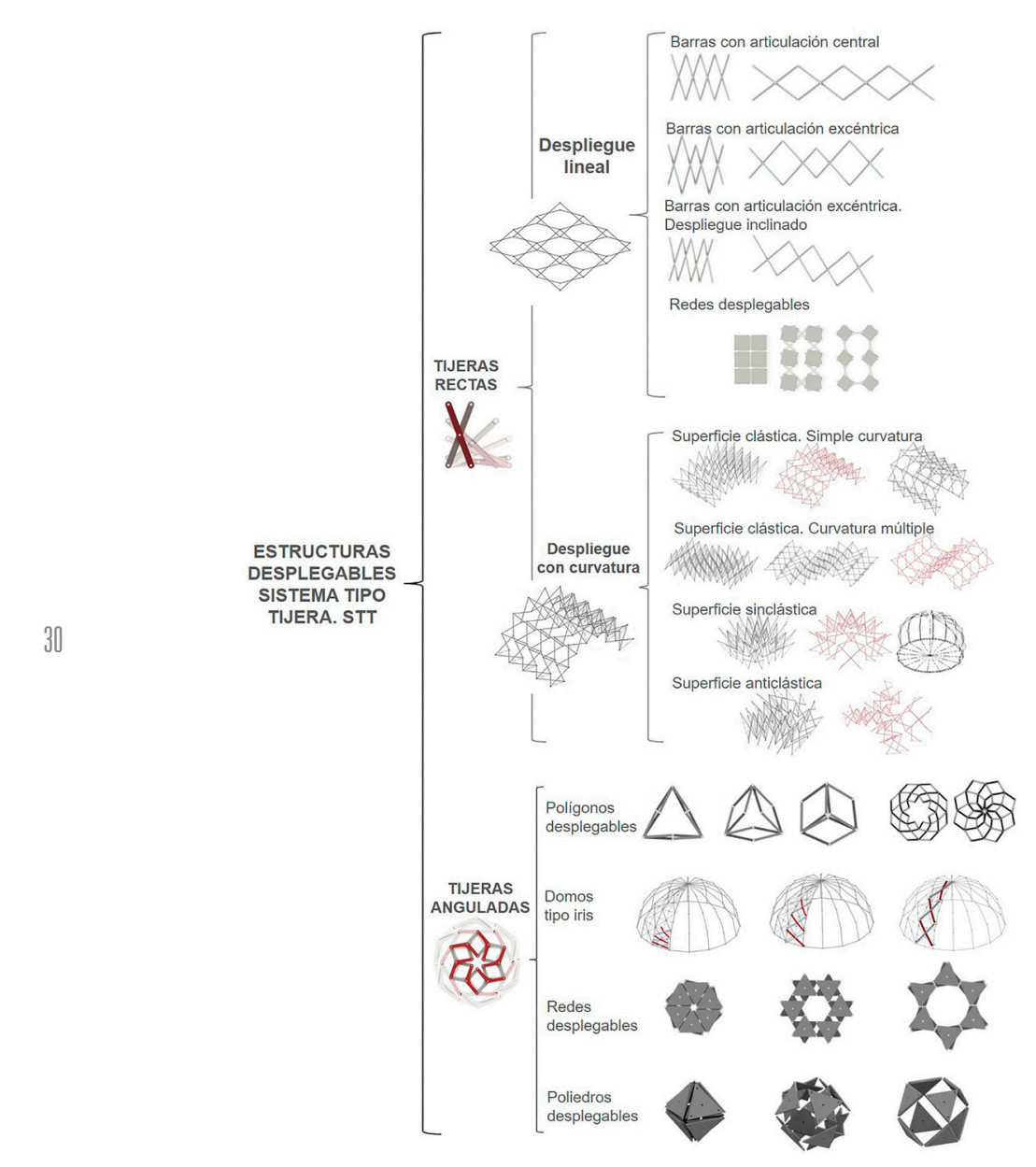




\section{Metodología}

A partir de la clasificación del STT y de las diferentes configuraciones posibles, el workshop aborda tres temáticas repartidas en una semana de trabajo.

Polígonos y poliedros desplegables. Agrupación de tijeras anguladas.

Superficies con despliegue lineal y curvatura variable. Agrupación de tijeras rectas.

Construcción del pabellón Xuê. Ensamble, montaje y despliegue de una estructura a escala real.

Considerando la importancia de visualizar las diferentes etapas de despliegue y comprender el comportamiento de este tipo de estructuras, el grupo de investigación SMiA, junto con el apoyo técnico del equipo del LEFAD, desarrolla como herramienta lúdica y académica, kits de piezas en MDF. Estos componentes utilizan el corte con la tecnología láser, la fabricación de nodos en impresión $3 \mathrm{~d}$ y conexiones tipo tornillos, para armar diferentes configuraciones de estructuras desplegables a través de un proceso de rápido y fácil ensamblaje.

El Workshop finaliza con la construcción de un pabellón desplegable en madera. El proyecto colaborativo entre los 
estudiantes participantes genera como resultado una aplicación novedosa que permite experimentar con este tipo de estructuras, probar nuevas técnicas de montaje y analizar el comportamiento real de la misma.

\section{Maquetas}

El planteamiento y fabricación de las maquetas diseñadas para este campo del conocimiento, permiten que los estudiantes puedan entender de forma más intuitiva el proceso de construcción y comportamiento de las estructuras desplegables con el STT. Posibilita una visualización más evidente de la composición geométrica, del concepto de módulo y de las formas de agrupación ideales para formar estructuras complejas. Explora diferentes formas de ensamblaje y conexiones para lograr el correcto proceso de pliegue y despliegue de una estructura determinada.

\section{Barras y planos}

Se define como barra o plano las piezas que corresponden a los componentes de la tijera. Dos barras articuladas o dos planos articulados en su punto central o excéntrico forman un sistema tipo tijera.

Para el desarrollo de las prácticas de los estudiantes con maquetas resistentes a una escala favorable para manipularlas y que soporten el constante movimiento de pliegue y 
despliegue, se proponen piezas con longitud de barra entre 20 a $23 \mathrm{~cm}$, con un ancho correspondiente a $10 \mathrm{~cm}$ y planos de las figuras geométricas inscritas en un diámetro de 16 $\mathrm{cm}$. Todas las piezas son de espesor de $3 \mathrm{~mm}$ en MDF con agujeros de $4 \mathrm{~mm}$ de diámetro (figura 10 ).
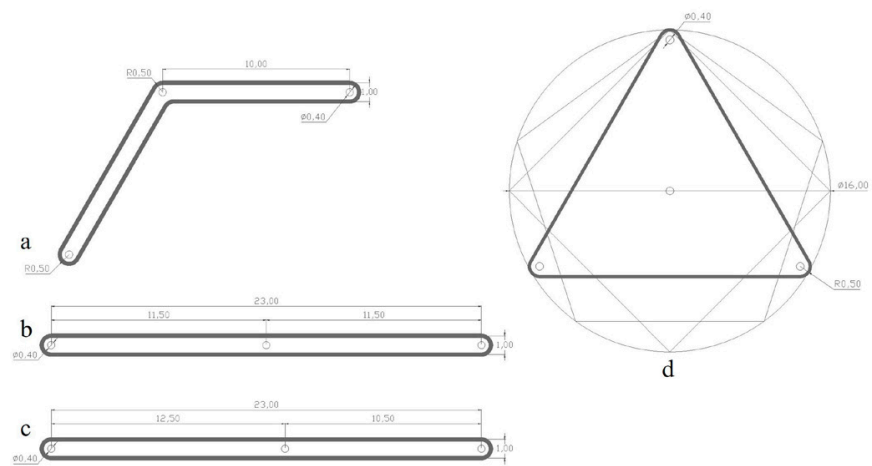

Figura 10 | Dimensiones de las piezas para la elaboración de maquetas. a) Barra para tijera angulada. b) Barra para tijera recta con articulación central. c) Barra para tijera recta con articulación excéntrica. d) Planos. Triangulo, cuadrado y pentágono para la configuración de poliedros desplegables. Fuente: Imagen elaborada por los autores.

\section{Nudos y conexiones}

Los nudos corresponden al punto de conexión que recibe las barras de las tijeras en diferentes direcciones y permite realizar agrupaciones tridimensionales. 
En la configuración de redes desplegables, los nudos son piezas mecánicas diseñadas específicamente para las maquetas de trabajo y materializadas a través de la tecnología de la impresión 3d (figura 11, a y b). Se utiliza como elemento de enlace entre nudo y barras, el sistema de tornillo y asegurado con tuerca. (figura 11, c)

En el caso de los poliedros desplegables se utiliza como nudo las anillas metálicas, que generan un mejor movimiento entre componentes. (figura 11, d)

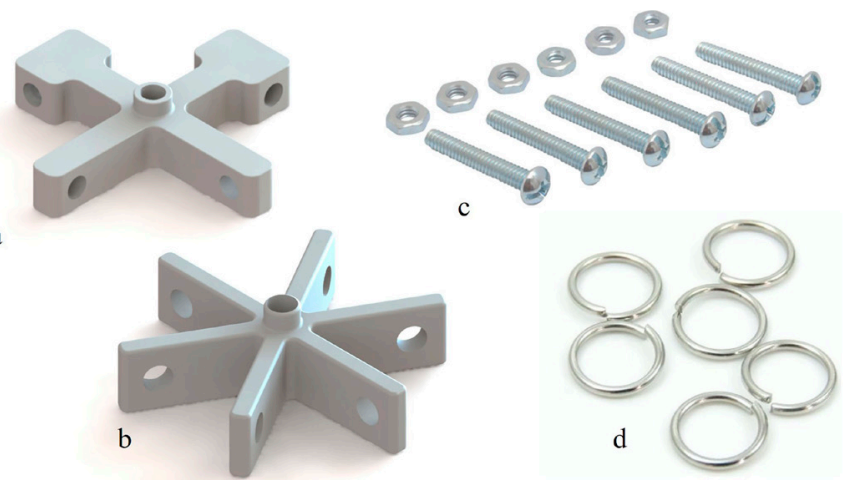

Figura 11 | a) Nodo tipo cruz. b) Nodo tipo hexagonal. c) Tornillos y tuercas. d) Anillas metálicas. Fuente: Imagen elaborada por los autores. 


\section{Polígonos desplegables}

Un polígono regular se caracteriza por tener todos sus lados y ángulos internos iguales. Para formar polígonos desplegables se debe disponer de tijeras anguladas.

El ángulo de cada barra y la cantidad de tijeras necesarias depende del número de lados del polígono regular a desarrollar. Es decir, si tomamos como ejemplo el triángulo, este estará configurado con tres tijeras anguladas y el ángulo de las seis barras corresponde a la siguiente fórmula:

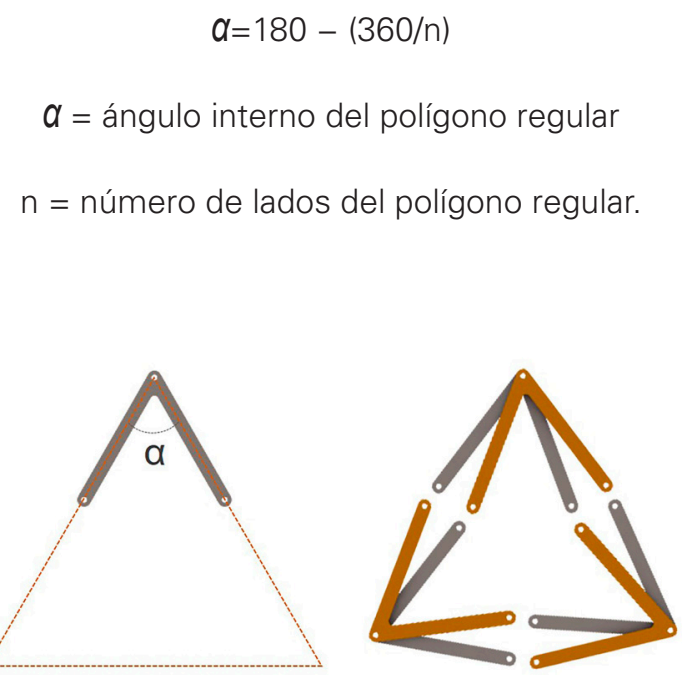

Figura 12 | Definición de la tijera angulada según la geometría del polígono a desarrollar. Fuente: Imagen elaborada por los autores. 
El ángulo interior del triángulo y que corresponde al ángulo para realizar las barras anguladas es de:

$$
\alpha=60^{\circ} \text { (figura } 12 \text { ). }
$$

De esta forma, se organizan los kits de barras anguladas, tornillos y tuercas por polígonos, para generar la geometría deseada y explorar variedades de agrupaciones con polígonos desplegables.

\section{Triangulo desplegable}

Es posible generar variaciones de la geometría resultante si se mantiene en ángulo de la barra y se procede a modificar la geometría del perímetro, por ejemplo, formando barras arqueadas (Tabla 2). El resultado es el mismo triángulo desplegable que en su etapa final de despliegue genera una geometría similar a una circunferencia. El proceso de transformación de la geometría perimetral de la barra se aplica en los siguientes polígonos. 


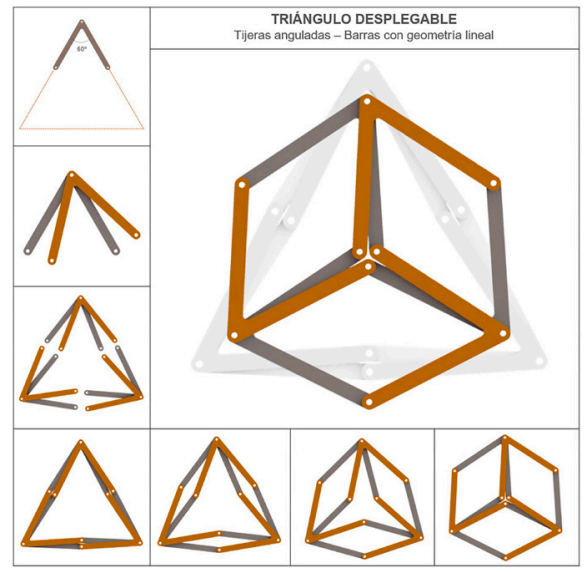

Tabla 01 | Triángulo desplegable. Geometría de la barra angulada del tipo lineal. Fuente: Imagen elaborada por los autores.

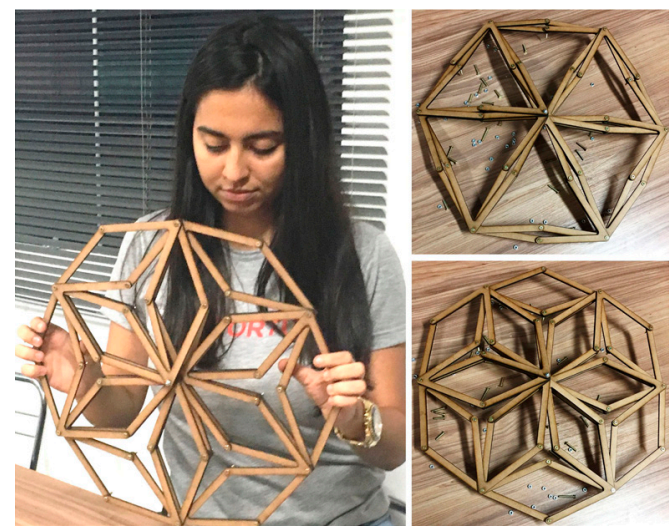

Figura 13 | Hexágono desplegable configurado a partir de la agrupación de triángulos desplegables. Geometría de la barra angulada del tipo lineal. Fuente: Archivo personal los autores. 


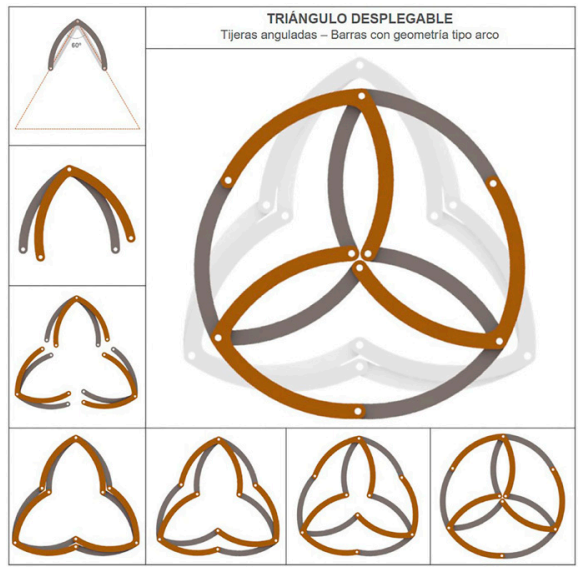

Tabla 02 | Triángulo desplegable. Geometría de la barra angulada del tipo arco. Fuente: Imagen elaborada por los autores.

30

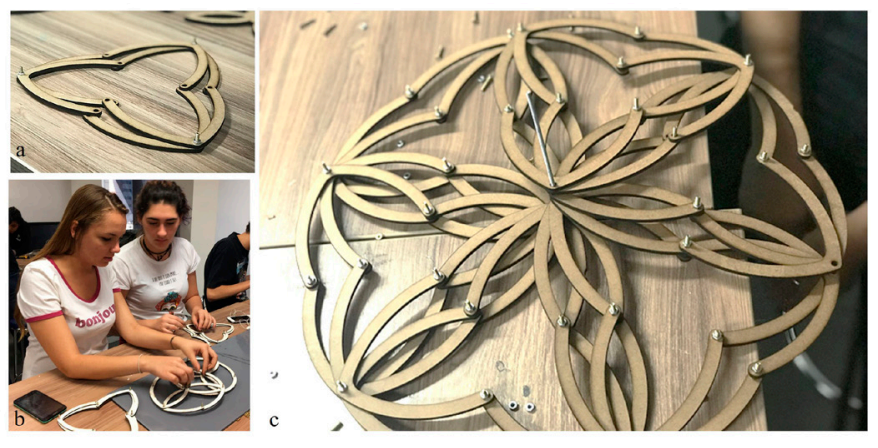

Figura 14 | Hexágono configurado a partir de la agrupación de triángulos desplegables. Geometría de la barra angulada del tipo arco. a) Módulo triángulo. b) Agrupación de triángulos. c) Hexágono desplegable. Fuente: Archivo personal los autores. 


\section{Cuadrado desplegable (tabla 3 y 4 )}

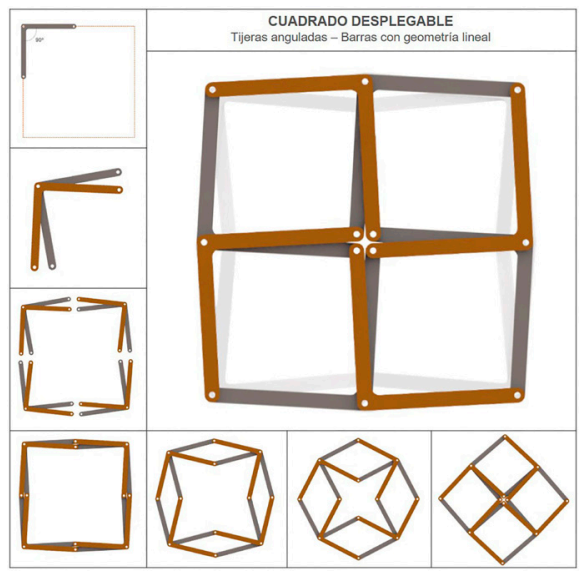

Tabla 03 | Cuadrado desplegable. Geometría de la barra angulada del tipo lineal. Fuente: Imagen elaborada por los autores.

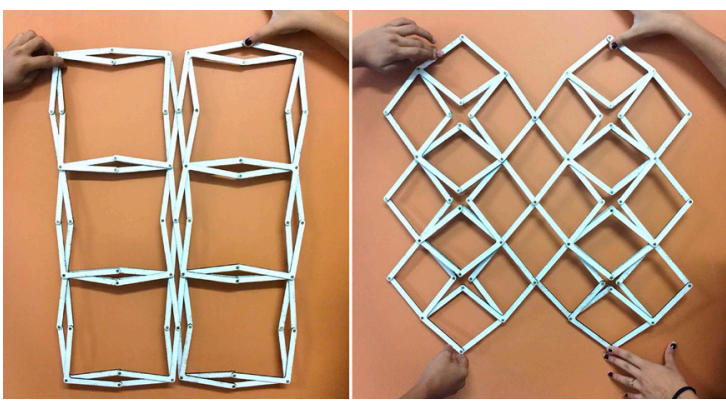

Figura 15 | Agrupación de cuadrados desplegables. Geometría de la barra angulada del tipo lineal. Etapas de despliegue abierta y cerrada. Fuente: Archivo personal de los autores. 


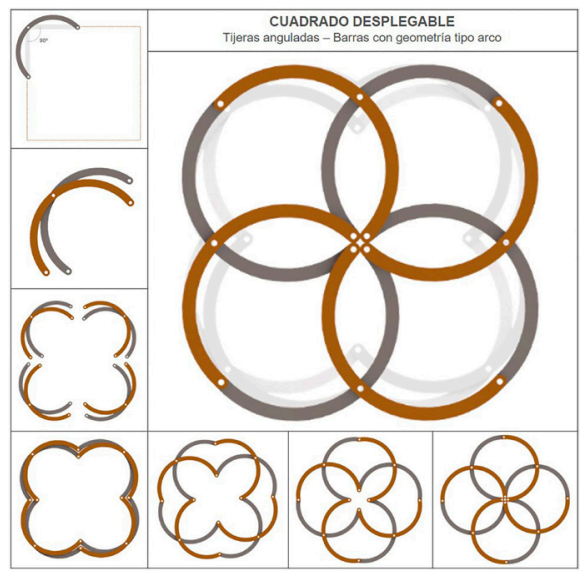

Tabla 04 | Cuadrado desplegable. Geometría de la barra angulada del tipo arco. Fuente: Imagen elaborada por los autores.

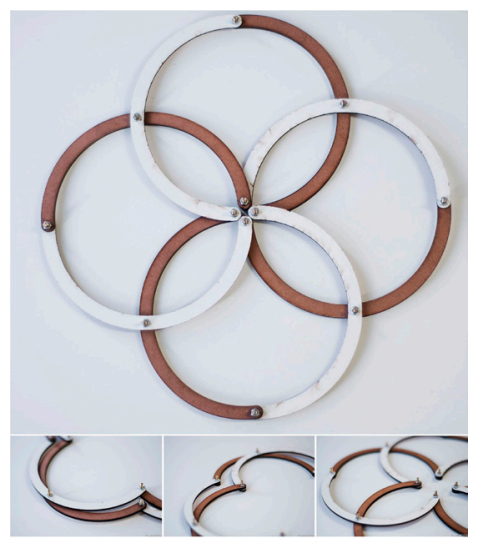

Figura 16 | Cuadrado desplegable. Geometría de la barra angulada del tipo arco. Fuente: Fotografía tomada por Laura Costa. 

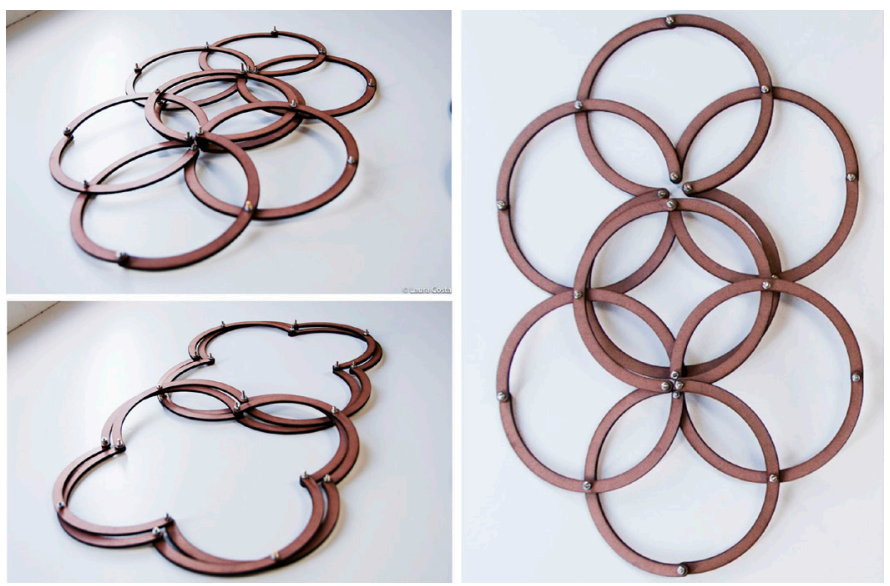

Figura 17 | Agrupación de cuadrados desplegables. Geometría de la barra angulada del tipo arco. Fotografía tomada por Laura Costa. 


\section{Hexágono desplegable y octágono desplegables}

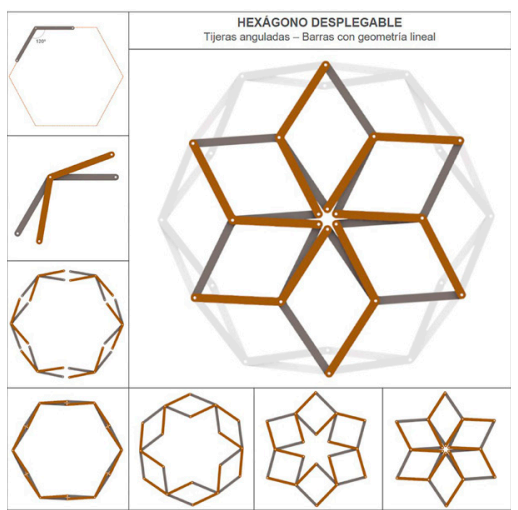

Tabla 05 | Hexágono desplegable. Geometría de la barra angulada del tipo lineal. Fuente: Imagen elaborada por los autores.

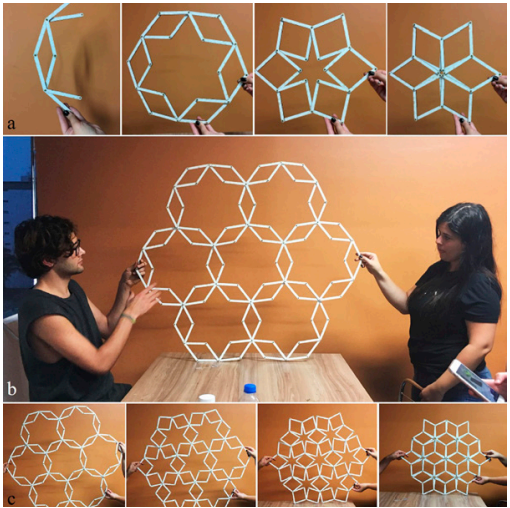

Figura 18 | a) Módulos de tijeras anguladas agrupadas que forman un hexágono desplegable; b) Agrupación de hexágonos; c) Etapas de despliegue agrupación de hexágonos.

Fuente: Archivo personal los autores. 


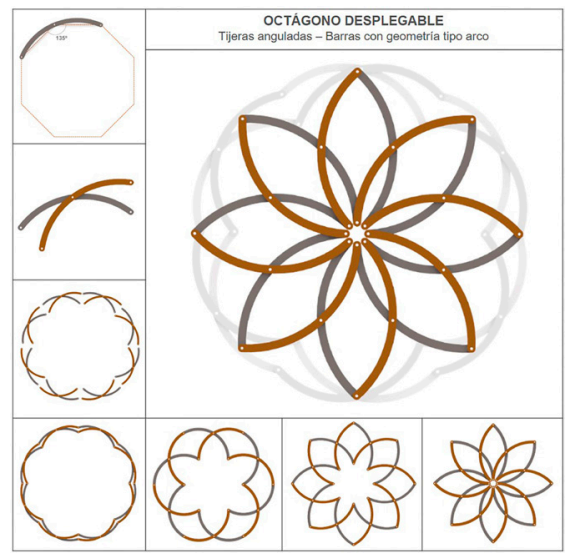

Tabla 06 | Octágono desplegable. Geometría de la barra angulada del tipo arco. Fuente: Imagen elaborada por los autores.
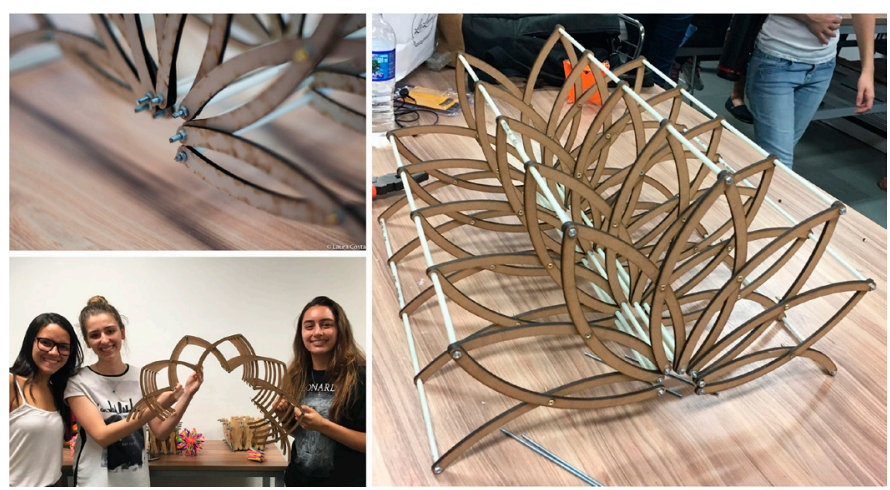

Figura 19 | Agrupación de secciones de octágonos, formando una bóveda tipo cañón. Fuente: Primera imagen a la izquierda fotografía tomada por Laura Costa. Imágenes adyacentes: Archivo personal los autores. 


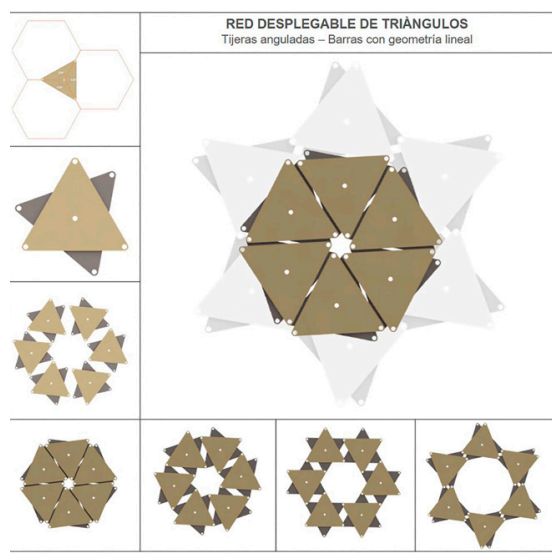

Tabla 07 | Red desplegable de triángulos.

Fuente: Imagen elaborada por los autores.
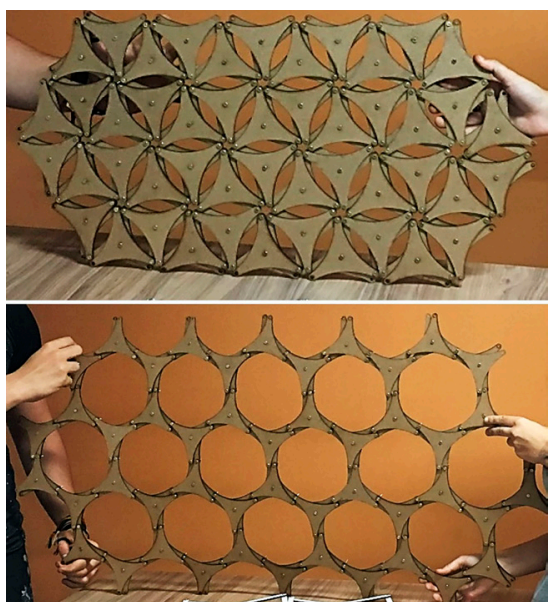

Figura 20 | Red de triángulos que forman una agrupación de hexágonos desplegables. Fuente: Archivo personal los autores. 


\section{Poliedros desplegables}

Los poliedros desplegables explorados en este taller corresponden a los poliedros regulares o sólidos platónicos. El principio para configurarlos se basa en remplazar las caras por elementos tipo tijera, en este caso, planos articulados, aunque también es posible explorar poliedros desplegables remplazando las aristas o los vértices, por tijeras. Para la actividad realizada en clase solo se realizaron poliedros regulares desplegables a partir de las caras (figura 21).

a

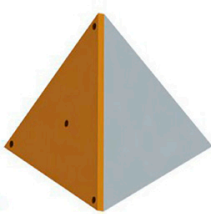

b
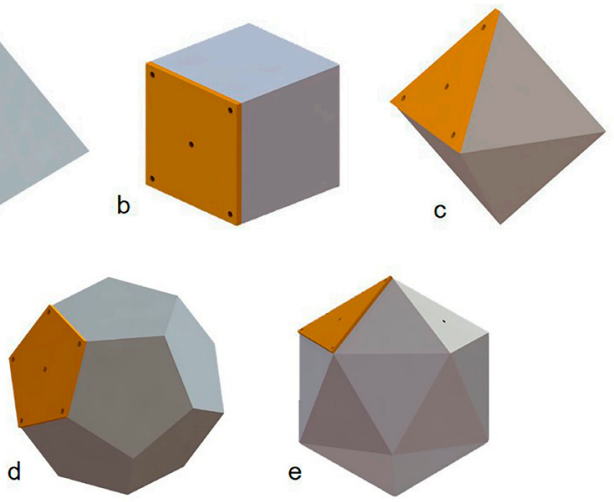

Figura 21 | Sólidos platónicos o poliedros regulares. a) Tetraedro. b) Hexaedro o cubo. c) Octaedro. d) Dodecaedro. e) Icosaedro. Fuente: Imagen elaborada por los autores. 
Al igual que los polígonos desplegables, también es posible variar la geometría de los componentes de la tijera en los poliedros manteniendo los puntos de articulación de la geometría original. Se propone configuraciones basadas en la forma de los pétalos que varían según el poliedro correspondiente (figura 22).
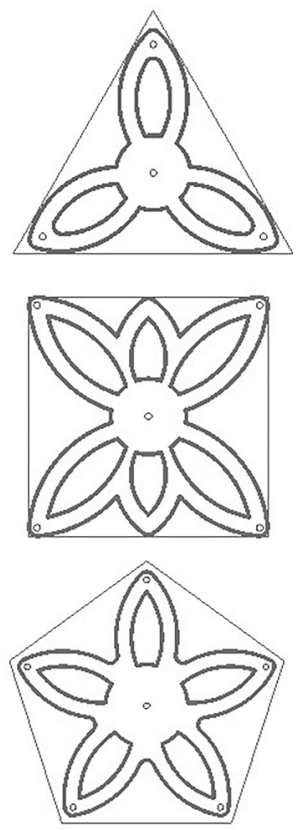

Figura 22 | Modificación de la geometría de las caras de poliedros, manteniendo la ubicación de los puntos de articulación de la geometría original. Fuente: Imagen elaborada por los autores 


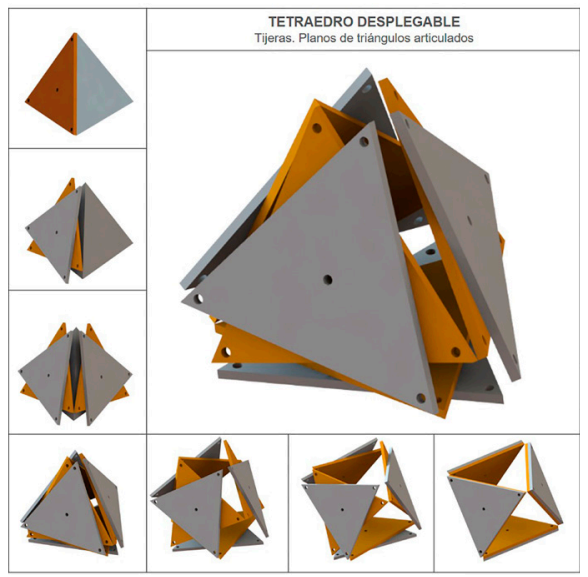

Tabla 08 | Tetraedro desplegable.

Fuente: Imagen elaborada por los autores.

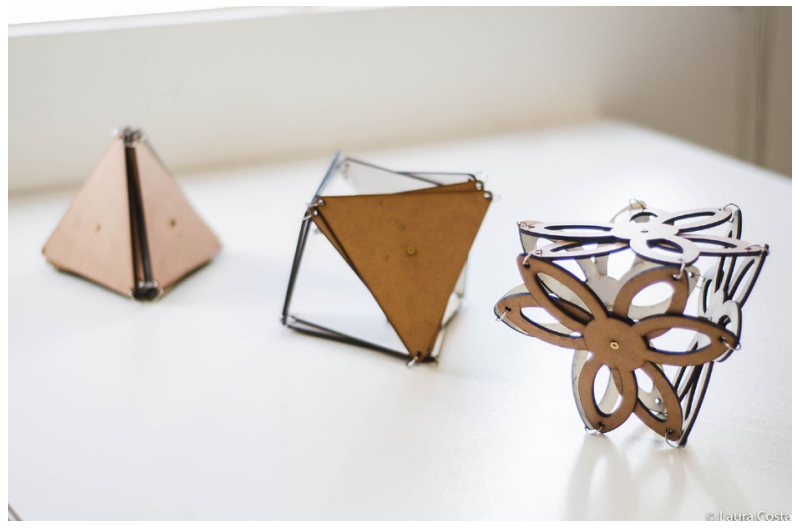

Figura 23 | Maquetas tetraedro desplegable.

Fotografía tomada por Laura Costa. 


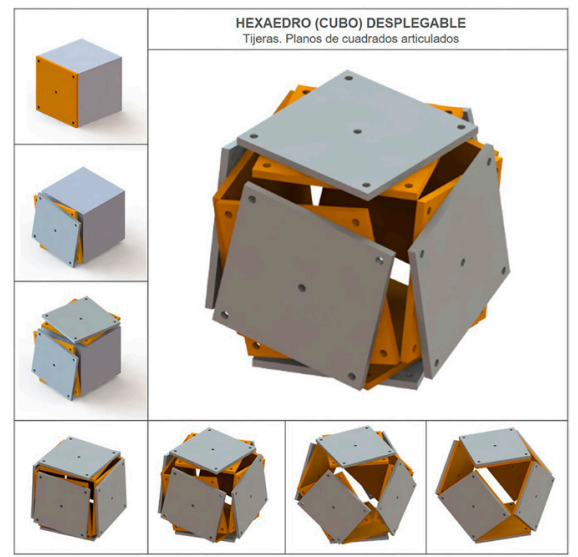

Tabla 09 | Hexaedro (cubo) desplegable.

Fuente: Imagen elaborada por los autores.

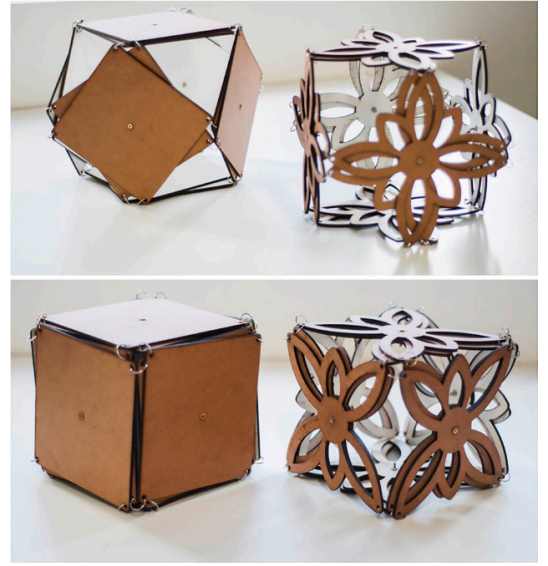

Figura 24 | Cubo desplegable. Geometría de la cara de poliedro original y geometría de la cara modificada. Fotografía tomada por Laura Costa. 


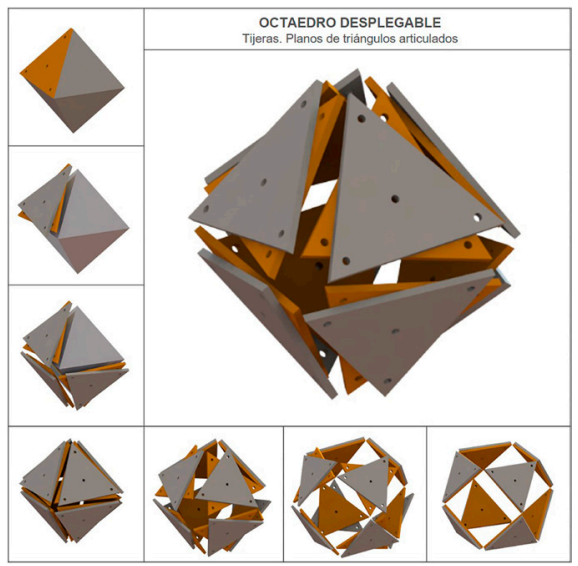

Tabla 10 | Octaedro desplegable.

Fuente: Imagen elaborada por los autores.

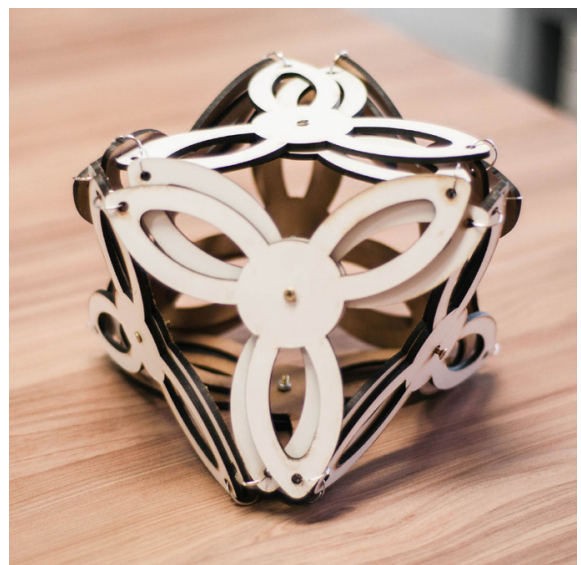

Figura 25 | Octaedro desplegable. Geometría de cara modificada. Fotografía tomada por Laura Costa. 


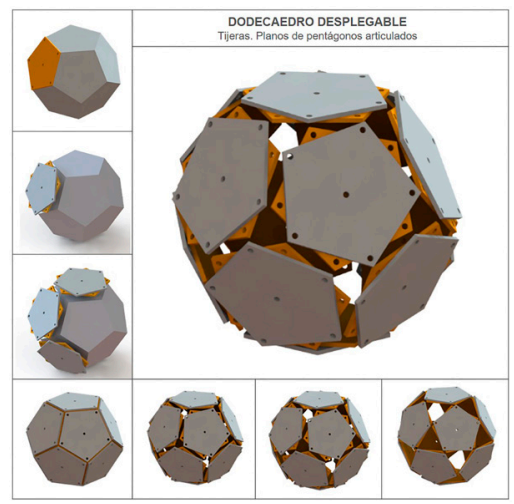

Tabla 11 | Dodecaedro desplegable.

Fuente: Imagen elaborada por los autores.

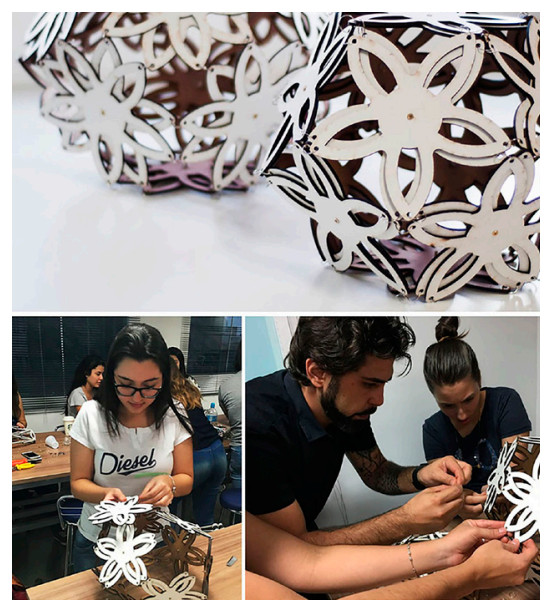

Figura 26 | Dodecaedro desplegable. Imagen superior. Fotografía tomada por Laura Costa. Imágenes inferiores Fuente: Archivo personal los autores 


\section{Agrupaciones con tijeras rectas}

Las agrupaciones de tijeras que se describen a continuación, parten de módulos que configuran unidades de agrupaciones planas que se enlazan en diferentes direcciones. La combinación de agrupaciones de tijeras rectas con articulación central o con articulación excéntrica permite formar variados tipos de superficies (figura 27).

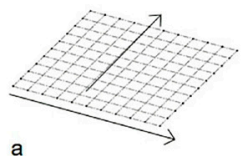

a

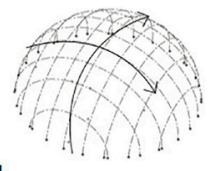

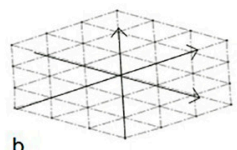

b

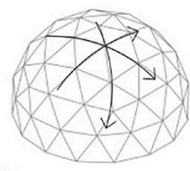

e
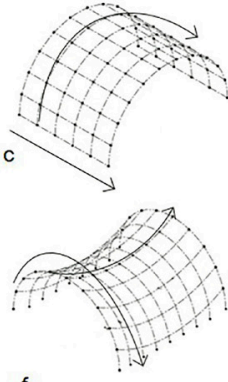

$f$

Figura 27 | a) Superficie plana, red cuadrangular. b) Superficie plana, red triangular. c) Superficie con curvatura simple, red cuadrangular. d) Superficie sinclástica, red cuadrangular. e) Superficie sinclástica, red triangular. f) Superficie anticlástica, red cuadrangular. Fuente: Imagen elaborada por los autores.

En esta publicación se describen cuatro posibilidades: Superficies planas, superficie con simple curvatura, superficies sinclásticas y superficie anticlástica, agrupadas de tal forma que configuran redes cuadrangulares y redes trian- 
gulares.

Para obtener un proceso de fácil ensamble en la construcción de este tipo de maquetas, se diseñan nodos específicos y adecuados para el tamaño de las barras. Estos son materializados con la impresión $3 d$ y permiten conectar módulos de tijeras formando trazados cuadrangulares y triangulares (figura 28).

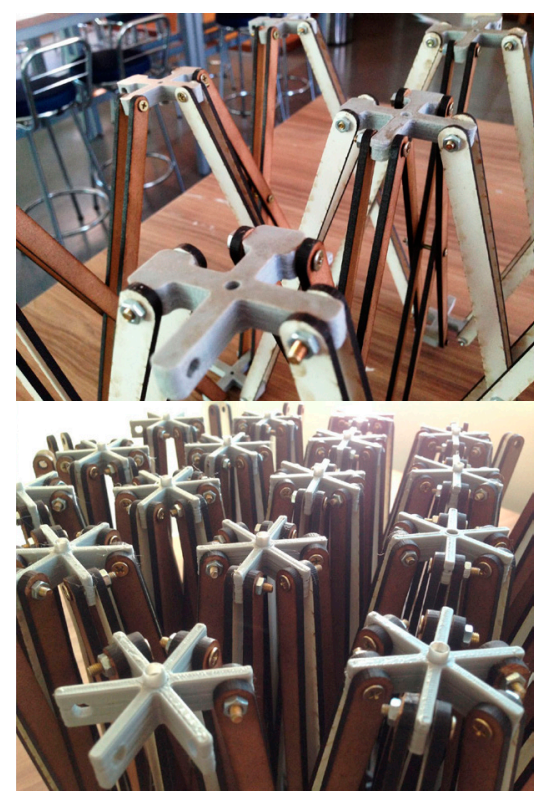

Figura 28 | Nodos realizados con impresión 3d. Nodo tipo cruz y nodo tipo hexagonal. Fuente: Archivo personal los autores 


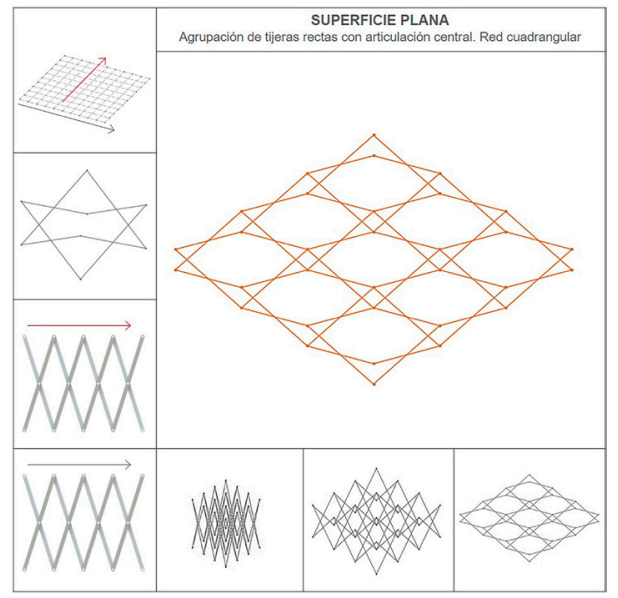

Tabla 12 | Superficie plana. Red cuadrangular. Fuente: Imagen elaborada por los autores.

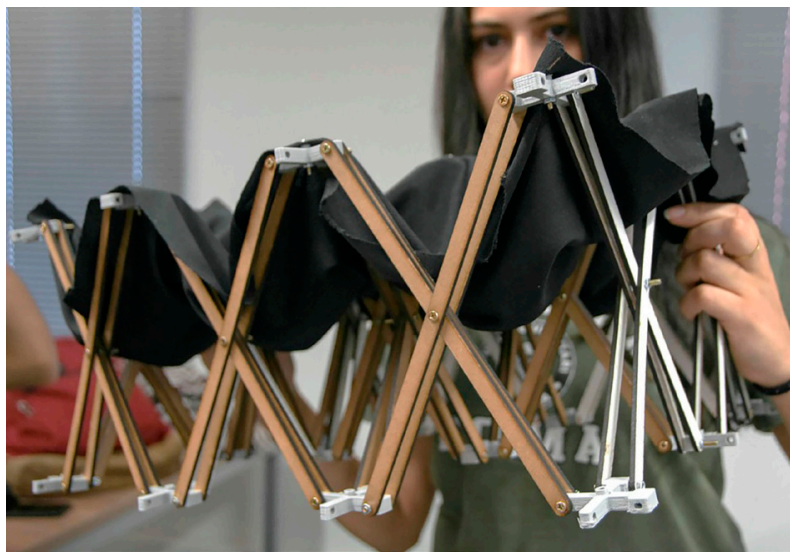

Figura 29 | Maqueta configuración de superficie plana. Red cuadrangular. Propuesta de cubierta con lycra. Fuente: Archivo personal los autores. 


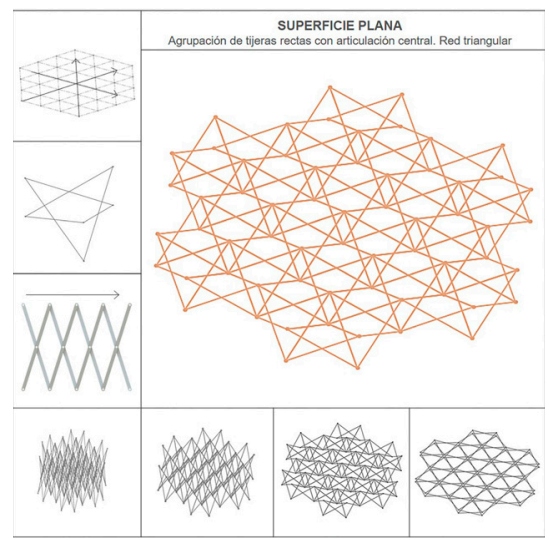

Tabla 13 | Superficie plana. Red triangular.

Fuente: Imagen elaborada por los autores.

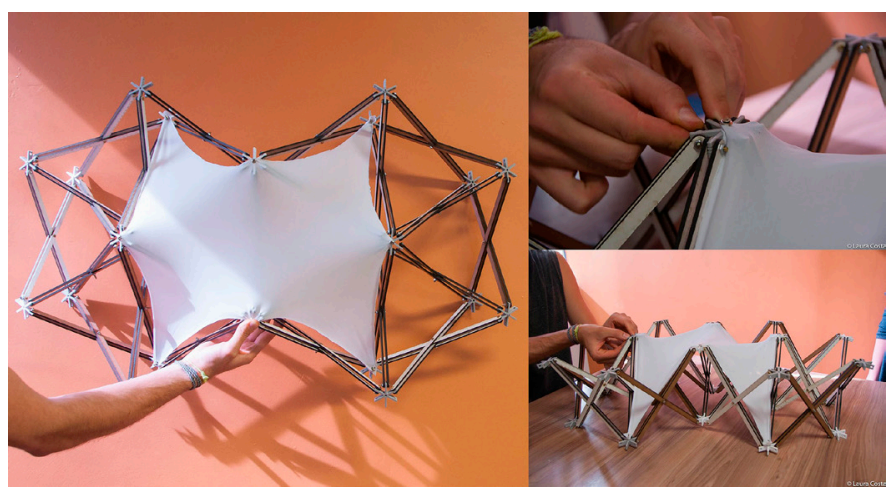

Figura 30 | Maqueta configuración de superficie plana. Red triangular. Propuesta de cubierta con lycra. Fuente: Fotografías tomada por Laura Costa. 


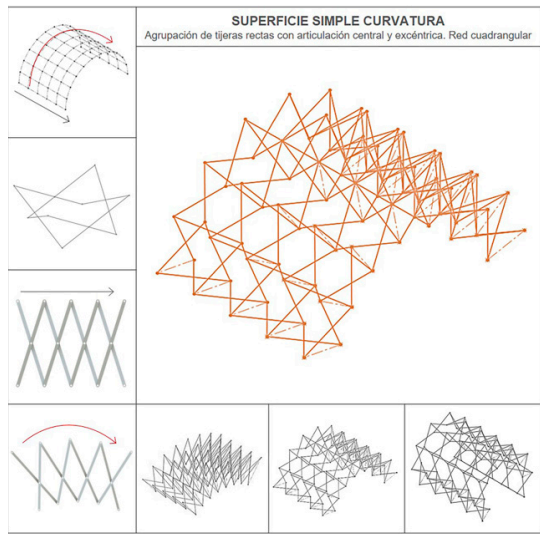

Tabla 14 | Superficie simple curvatura. Red cuadrangular. Fuente: Imagen elaborada por los autores.

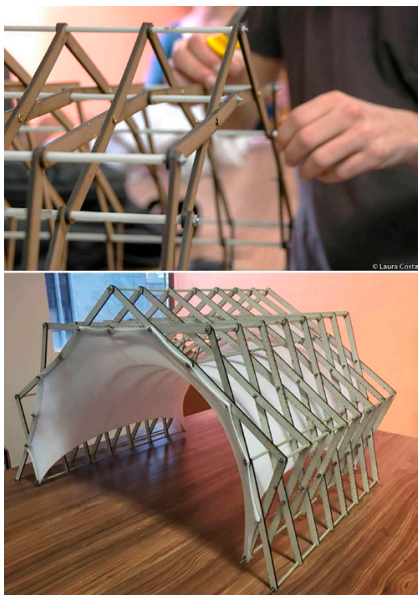

Figura 31 | Maqueta configuración de superficie con simple curvatura. Propuesta de cubierta con lycra. Fuente: Fotografías tomada por Laura Costa. 


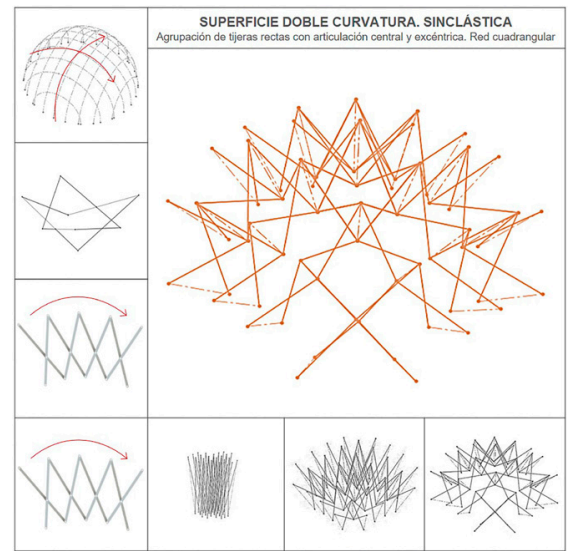

Tabla 15 | Superficie sinclástica. Red cuadrangular.

Fuente: Imagen elaborada por los autores.

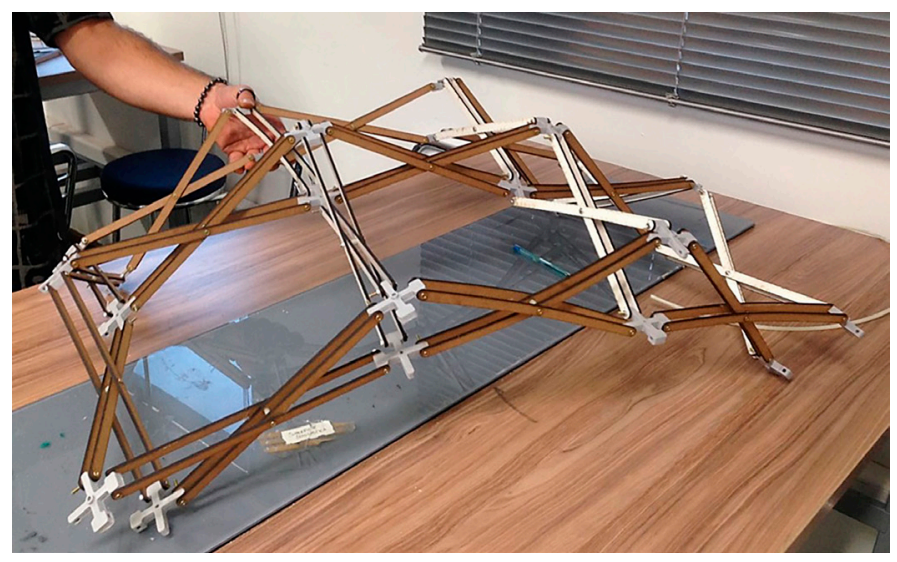

Figura 32 | Maqueta configuración de superficie sinclástica. Red cuadrangular. Fuente: Archivo personal los autores. 


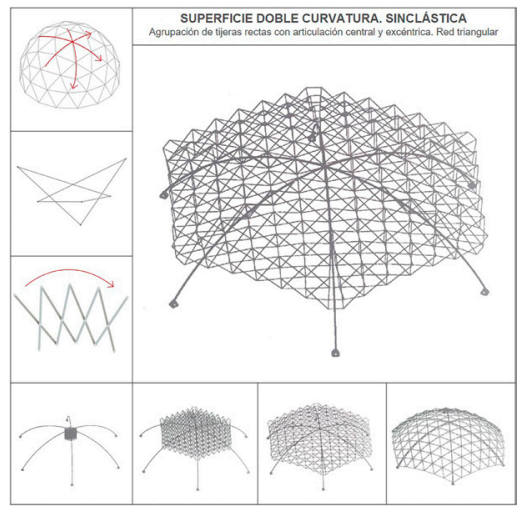

Tabla 16 | Superficie sinclástica. Red cuadrangular.

Fuente: Imágenes etapas de despliegue tomadas de (Candela et al, 1993)

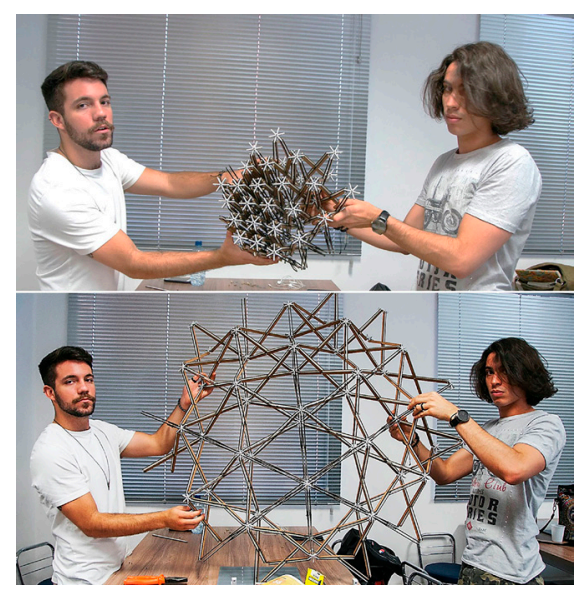

Figura 33 | Maqueta configuración de superficie sinclástica con tijeras rectas. Red triangular. Fuente: Fotografías tomada por Laura Costa. 


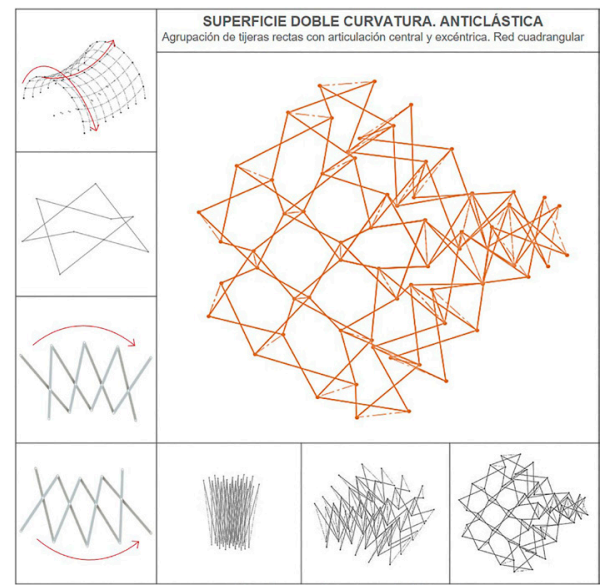

Tabla 17 | Superficie sinclástica. Red cuadrangular. Fuente: Imagen elaborada por los autores.

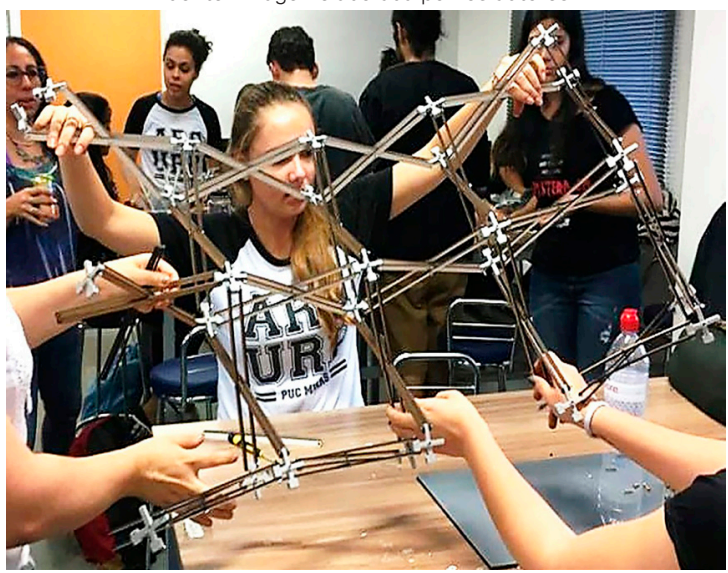

Figura 34 | Maqueta configuración de superficie anticlástica con tijeras rectas. Red cuadrangular. Fuente: Archivo personal los autores. 


\section{Pabellón Xuê}

La palabra $X u \hat{e}^{6}$ proviene del tupi guaraní, significa lentamente, sin prisas y se toma como referencia para proponer un espacio de permanencia, que invite a sentarse y a compartir experiencias.

Xuê es pabellón comedor, diseñado como una estructura desplegable en madera, compuesta de cuatro arcos plegables independientes que conforman una bóveda de cañón, con una altura libre de $2.30 \mathrm{~m}$ (figura 35). El pabellón ocupa un área de $15 \mathrm{~m}^{2}$ y su función es ofrecer un área de sombra apergolada para las mesas que se incorporan en su estructura.

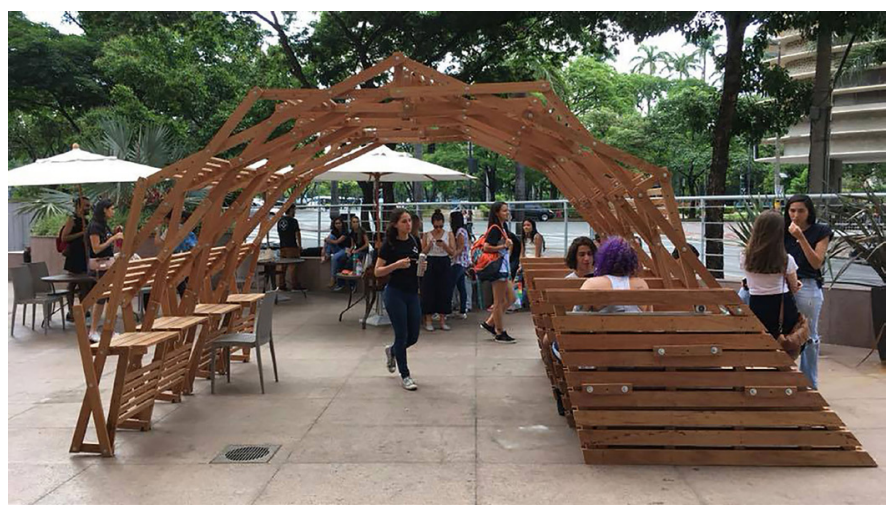

Figura 35 | Pabellón Xuê. Fuente: Archivo personal los autores.

6. Tomado de Glossário Tupi-Guarani llustrado, 2016 
Su diseño está basado en la geometría de un heptágono regular, que permite definir el arco ideal para el planteamiento de la estructura plegable (figura 36). La geometría de polígonos regulares es una propuesta de investigación que permite definir el número de módulos de tijeras necesarios, las dimensiones y las características de la excentricidad de los puntos de articulación entre los componentes de la tijera para obtener la geometría deseada (Torres y Peña, 2017).
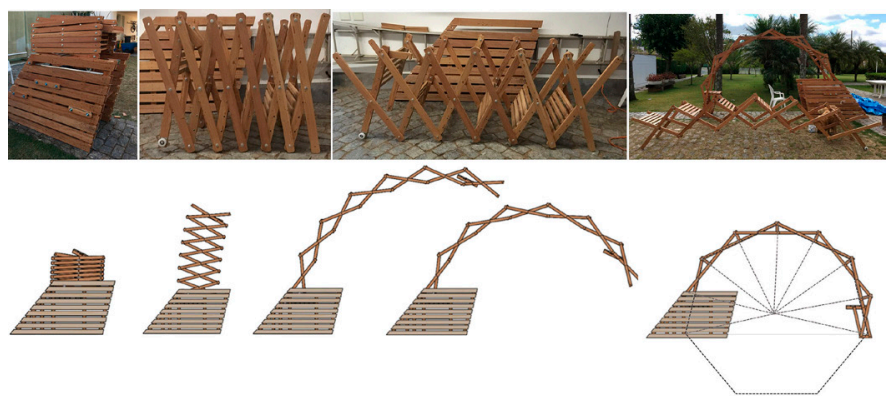

Figura 36 | Pabellón Xuê. Geometría del arco plegable a partir del heptágono.

Fuente: Archivo personal los autores.

Cada arco se compone de siete módulos de tijeras, cada módulo tiene doble capa de tijeras separadas con travesaños, que generan el conjunto de un arco apergolado estable. Cada extremo de arco se apoya sobre dos paneles de madera que contienen el riel para permitir el proceso de plegado del arco y adicionalmente soportar las tablas que forman las mesas y sillas de los comedores (figura 37). 


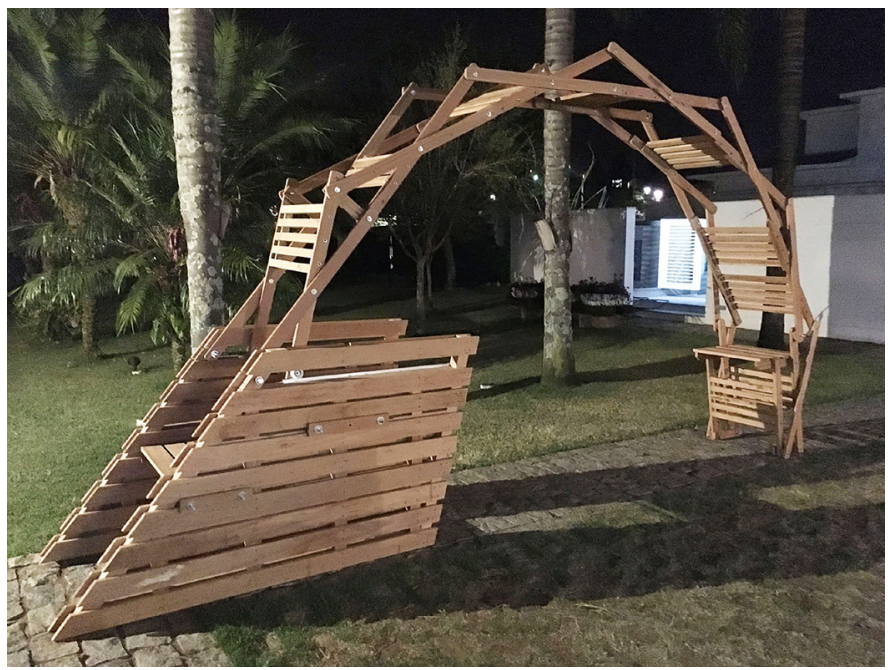

Figura 37 | Módulo arco.

Fuente: Archivo personal los autores.

La agrupación de cuatro arcos configura la totalidad del pabellón en forma de bóveda de cañón. Para el sistema de ensamble entre barras, se desarrollan conexiones sencillas a partir de pernos, arandelas y tuercas de seguridad, que permiten el movimiento de despliegue y pliegue de los arcos. La fabricación y pre-ensamble tardo dos semanas y el montaje tres horas. 
El proceso de construcción del pabellón complementa el taller impartido, permitiendo a los estudiantes tener la experiencia en el montaje de una aplicación real con estructuras desplegables utilizando un sistema tipo tijera.

El proceso consiste en llevar los paneles y los arcos ya ensamblados, alinear los paneles y estabilizar el conjunto con las tablas de las mesas y varillas que aseguran el pabellón longitudinalmente (figura 38). Se procede a desplegar los arcos, asegurarlos mediante barras de bloqueo y montar finalmente los arcos sobre los paneles, posicionándolos a su estado final (figura 39).

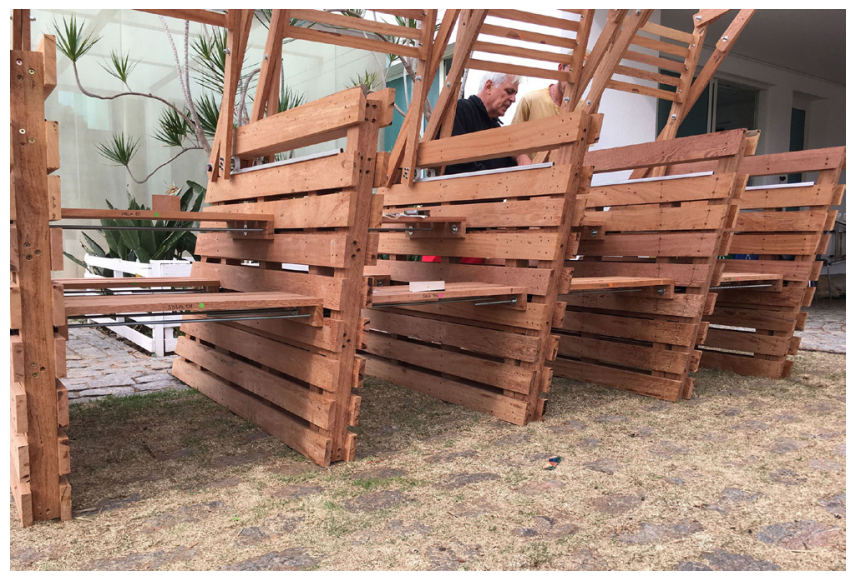

Figura 38 | Posicionamiento de los paneles, mesas, sillas y arcos. Fuente: Archivo personal los autores. 


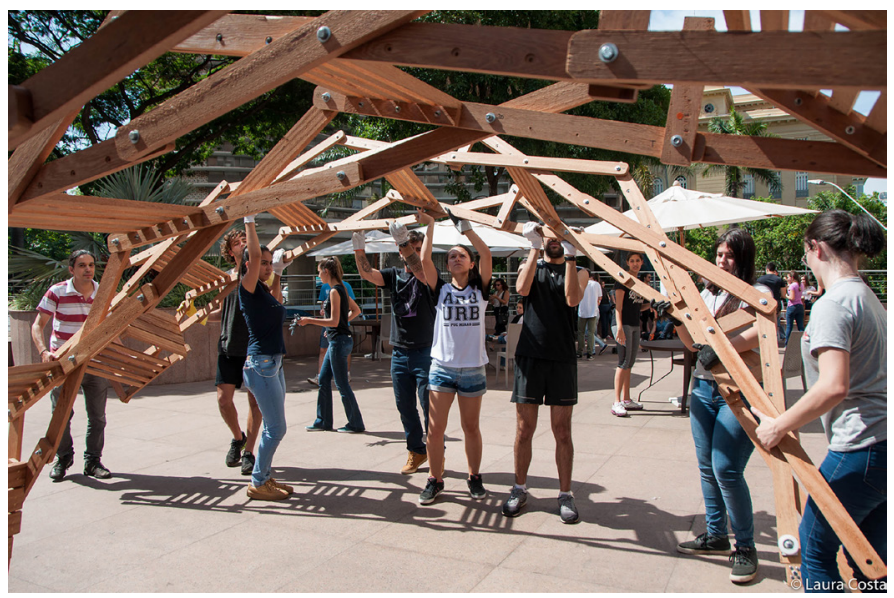

Figura 39 | Arcos desplegados y asegurados con las barras de bloqueo para garantizar su posición. Fuente: Archivo personal los autores.

El pabellón Xuê es una estructura liviana, plegable, realizada con materiales sostenibles y con la posibilidad de un rápido montaje y desmontaje para trasladarla a otro emplazamiento (figura 40). Su construcción se logró gracias al apoyo, coordinación y logística de lo Departamento de Arquitectura y Urbanismo de la Pontificia Universidad Católica de Minas Gerais, al Laboratorio de Fabricación Digital LEFAD y a la participación de los estudiantes (figura 41). 


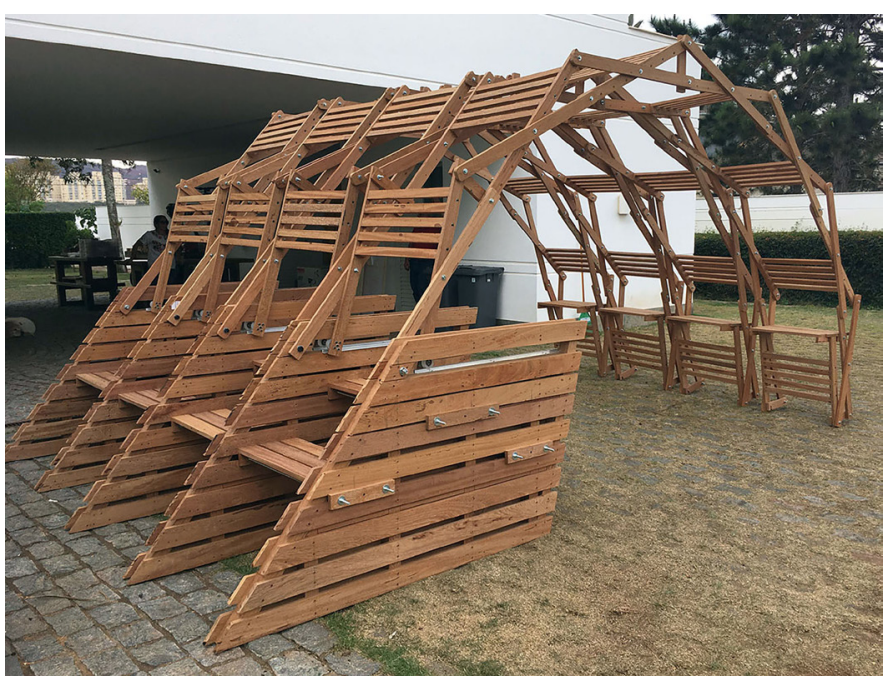

Figura 40 | El pabellón Xuê. Agrupación de cuatro módulos de arco. Fuente: Archivo personal los autores. 


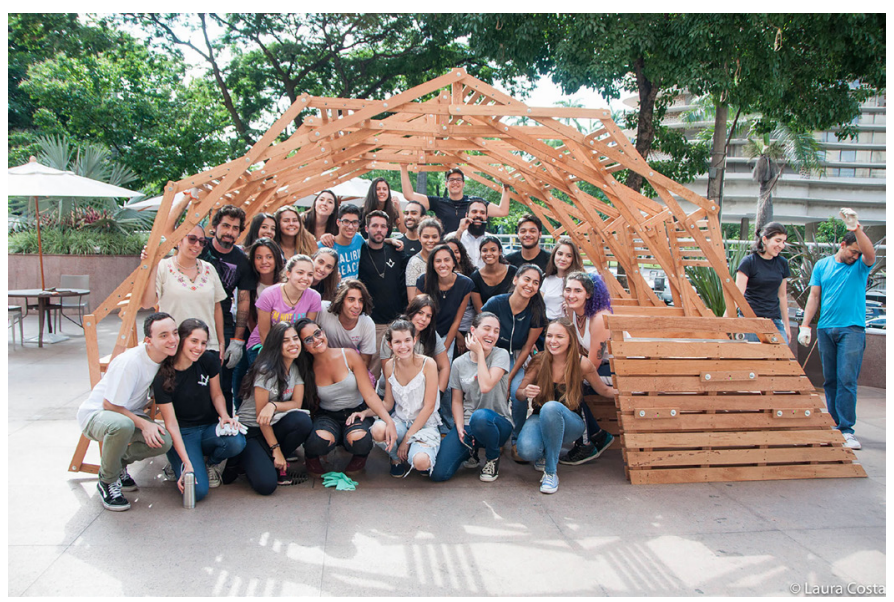

Figura 41 |El pabellón Xuê. Estudiantes de arquitectura que participaron en el Workshop de estructuras desplegables 2017. Fuente: Archivo personal los autores. 


\section{Conclusiones}

La experiencia del taller permitió dar a conocer nuevas estrategias de diseño, partiendo de la plegabilidad como una alternativa para crear estructuras transformables y modulares.

El sistema tipo tijera permite explorar diferentes configuraciones espaciales basadas en la comprensión de la geometría básica de polígonos y poliedros, así como la comprensión de superficies planas y con curvatura.

La propuesta de kits para configurar estructuras desplegables con el STT, desarrolla una nueva propuesta de metodología para la compresión de este tipo de estructuras. La exactitud de las piezas con corte laser y de impresión 3d, permite elaborar maquetas con mayor calidad del detalle y precisión. Esto permite que se pueda observar el comportamiento de la estructura a escala y analizar los posibles fallos.

Adicionalmente los kits ofrecen un sistema de fácil ensamble, de esta forma el estudiante adquiere una mejor compresión del armado y visualiza la importancia del módulo y la agrupación, además de analizar las diferentes etapas de despliegue.

El uso de las tecnologías utilizadas dentro del laboratorio 
optimiza los procesos de diseño y de maquetación, incentivando a generar nuevas exploraciones académicas para mejorar la técnica o crear nuevas combinaciones espaciales transformables.

La construcción de un pabellón al servicio de la comunidad universitaria, permite a los estudiantes comprender el cambio de escala y enfrentarse a reto del montaje real de este tipo de estructuras, además de analizar el comportamiento de la estructura. El objetivo del grupo de investigación SMiA, es potencializar el diseño de este tipo de estructuras a través de aplicaciones reales.

Las estructuras desplegables son un campo de estudio amplio, con múltiples líneas de investigación, exploraciones y análisis científicos. El taller impartido se caracteriza como un primer acercamiento para comprender a través de la maqueta los conceptos básicos de los sistemas desplegables tipo tijera.

\section{Referencias}

ASSOCIACIÓ de Consultors d'Estructures. Quaderns d'Estructures. Número 49. Barcelona. 2014.

CANDELA, F.; PÉREZ, E.; CALATRAVA, S.; ESCRIG, F (Ed.). y PÉREZ, J. Arquitectura Transformable. Textos de arquitectura. Publicación de la Escuela Técnica Superior de Arquitectura de Sevilla. España.1993

EDIÇÕES, LeBooks (Autor). GlossárioTupi-Guarani llustrado: Incluindo nomes indígenas de pessoas e cidades. Coleção História Viva) Versión Kindle. 2016 
ESCRIG, F. (Ed.). Modular, ligero y transformable. Un paseo por la arquitectura ligera móvil. Sevilla, España: Universidad de Sevilla. 2012.

FENCI, GE.; CURRIE, N. Deployable structures classification: a review. International Journal of Space Structures, v. 32, n. 2, p. 112-130, 2017.

GANTES, C.; KONITOPOULOU, E. Geometric design of arbitrarily curved bi-stable deployable arches with discrete joint size. International Journal of Solids and Structures. v. 41, n. 20, p. 5517-5540 2004.

PUERTAS DEL RIO, L., Estructuras espaciales desmontables y desplegables. Estudio de la Obras del arquitecto Emilio Pérez Piñero (tesis doctoral). Escuela Técnica Superior de Arquitectura de Madrid, España. 1989.

ROOVERS, K.; ALEGRIA, L. y DE TEMMERMAN, N. From Surface to Scissor Structure. Proceedings of the First Conference Transformables. In the Honor of Emilio Perez Piñero, pp. 275-280, 2013.

STEVENSON, CM. Morphological principles: current kinetic architectural structures. International Adaptive Architecture Conference. The Building Centre, London, pp. 1-12, 2011.

TORRES, N., PEÑA, D.M. Deployable Arches Based on Regular Polygon Geometry. ARCHI DOCT, 14 Febrer, v. 4, n. 2, p. 89-105. 2017. 
